\title{
NATURALISM AND WONDER: PEIRCE ON THE LOGIC OF HUME'S ARGUMENT AGAINST MIRACLES
}

\section{CATHY LEGG}

How should we proceed when confronted with a phenomenon (or evidence which points towards a phenomenon) which baffles us? The term "miracle" is a convenient term on which to hang this question. It has a religious meaning, and the arguments I will be discussing are applicable to the case of deciding, for example, whether to believe in the Judaeo-Christian God, based on the reports of miracles offered by the Bible $^{1}$. However, one can generalise from this case to deeper issues about our attitude to the apparently inexplicable. By the apparently inexplicable I mean that which contradicts our most well-confirmed beliefs. This general question is the theme of this paper.

My strategy will be to outline Hume's famous argument against our ever accepting testimony regarding miracles. This argument delivers results which are apparently pleasing to many twentieth century philosophical naturalists, (where "naturalism" is defined - somewhat vaguely as it is very much an "umbrella" term - as the view that privileges the experimental methods of science in discovering the nature of the Universe $^{2}$ ). Yet I will present a case that Hume's argument is in fact in tension with a fully naturalist methodology of inquiry ${ }^{3}$. In fact, this was convincingly argued in the late nineteenth century by Charles Sanders Peirce. Peirce has been regarded as an American polymath of prodigious originality but scattered output. However his career can be brought into new focus by viewing it as organised around an overwhelming interest in logic. This can easily be missed as by "logic" Peirce meant something broader than what is usually meant by the term today. Peirce defined logic as the science of reasoning well, which includes how best to employ reason in the service of scientific discovery. Thus, scientific methodology (which he identified with the methodology of inquiry generally) was an important part of logic for Peirce.

Though Hume's argument against miracles has been widely regarded by philosophers as a veritable piece of common-sense, Peirce provides an argument from a thoroughly experimental perspective (using as a case study a branch of 19th century philology) that Hume's "method of balancing likelihoods" is in fact poor science when applied to human testimony, and indeed is useless in all but a small subset of investigations (those that are tightly quantifiable, such as investigations of the relative frequencies of dice-throws). Logically speaking, Hume's method neglects the important role played in scientific inquiry by abduction. Abduction is the generation of new hypotheses and in the employment of this logical form, bafflement (epistemically confronting something which contradicts our current well-confirmed 
beliefs) in fact plays a vital role. With this in mind, Peirce suggests a better method than Hume's for the naturalist to investigate "miraculous" testimonies: searching for the best explanation for all given facts, including the testimonies themselves.

I argue that these results are as relevant to twentieth century naturalism as they were in Peirce's day, offering to that effect a case study of a contemporary naturalist (Frank Jackson) who is Humean in his attitude to that which contradicts our most well-confirmed beliefs, and I conclude with some remarks about the relationship between naturalism and wonder.

\section{Hume's Argument}

Hume's definition of a miracle as an event which violates or breaks the laws of nature $^{4}$ has been highly influential in philosophy. He notes that we need a distinction between the "marvellous" (the highly unusual or surprising, such as for instance if, watching a crab walking across the sand, one were to notice the crab trace out the word, "Hello") and the "miraculous", (such as if while one was teaching, chalk were to rise into the air, make its way to the blackboard in flagrant contradiction to the laws of gravity and write, "Ignore this professor. The end is nigh".)

In a footnote Hume claims that miracles are miracles whether we know about them or not. For a ship to rise spontaneously up in the air pretty obviously transgresses the laws of nature. But for a feather to rise half a centimetre off a table in the absence of any wind might be equally against the laws of gravity (and thus a miracle), though we probably would not notice it. ${ }^{5}$ However, we will see later on that Hume's argument against miracles does not actually rest on this "metaphysical" definition of miracles, but on a rather more "epistemic" one.

Hume offers rules to guide the understanding in its inevitable encounters with testimony that miracles have occurred. In all situations involving strange and surprising testimony he argues that one has to balance two beliefs: one's belief that this sort of thing is very unlikely, and one's belief that people normally tell the truth, and therefore that one's interlocutor is currently telling the truth. One has to choose between these beliefs on the basis of which is more probable, and thus which of them it would disrupt one's world-view the most to give up. ${ }^{6}$

Hume relates the tale of the Indian prince ${ }^{7}$ who was told by the first Europeans he met that in the winter in Europe it grows so cold that the rivers become completely solid, so that elephants might walk from one side to the other. Apparently the prince said that he had been told many improbable things about Europe and had believed them all, but that this was so unlikely he now knew the Europeans had been lying to him all along. Hume says that the Indian prince was actually reasoning justly. For 
India is so hot that the prince had never seen ice. Imagine how inconceivable it would be that water should behave in the way that it does when it freezes, if one had never witnessed freezing oneself.

How are we to measure and compare the probabilities of the testimonies we encounter? Hume's official theory of probability is strictly numerical in the following sense. He writes:

All probability...supposes an opposition of experiments and observations, where the one side is found to overbalance the other, and to produce a degree of evidence proportioned to the superiority. ${ }^{8}$

In other words, if we are experimenting by creating a situation which we think will demonstrate the proposition $\mathrm{A}$, then if 100 experiments conform to $\mathrm{A}$, and 50 experiments conform to not-A, this must throw some doubt on A. On the other hand, if 100 experiments conform to A and only one to not-A, we can hold A with a strong degree of assurance. ${ }^{9}$

How are we to make a judgement with respect to the probability of testimony regarding miracles? In fact herein lies Hume's coup de grace against all miracle reports ever to be encountered by the human understanding, which leads him to confidently describe his argument as:

...a decisive argument...which must at least silence the most arrogant bigotry and superstition, and free us from their impertinent solicitations. ${ }^{10}$

The decisive blow springs from the fact that a miracle is defined as something that violates (contradicts in some way) the laws of nature. When this is added to the probability-balancing approach to testimony, the result is that every piece of evidence (every "experiment", to use Hume's term) which confirms a law of nature is evidence against a miracle occurring that would break that law of nature. It is easy to see how miniscule the probability we should assign to such a miracle occurring must become, and how easily it will be outstripped by the small but nevertheless continually present possibility that we are being lied to, or that the person testifying to the miracle is simply mistaken.

It is important to note here that Hume's argument relies on a miracle being a violation of the laws of nature as we believe them to be. Thus, as noted earlier, Hume does not live up to his "metaphysical" definition of miracles, and relies on a rather more "epistemic" one ${ }^{11}$. For if he really thought of a miracle as being a violation of a law of nature per se, then there might well be laws of nature for which we had very small or no evidence, and which therefore would not automatically balance out testimony regarding miracles that violated those laws. In that case, the argument against miracles would not be "decisive", as Hume claims that it is. 
For example, if Hume had held to his metaphysical definition of a miracle, his argument would no longer have the decisive character he attributed to it in cases such as the following. Imagine that it is discovered that those who eat a particular brand of hamburger every day increase their chances of a heart attack by $95 \%$, and that this is indeed a "law of nature". Imagine that the fast food chain in question comes to hear of this result and stacks the medical conference at which the law is to be unveiled with pseudo-scientists, who outnumber the researchers by ten to one, and who each testify that they have eaten the hamburgers in question over decades to no ill effect. Rather than providing decisive protection against accepting "miracles" (purported violations of what is in fact a law of nature) such as these, Hume's argument positively recommends their acceptance. For the pure quantity of pseudo-scientific testimony in this situation far outweighs that of the researchers. Only if the law the pseudo-scientists were testifying against were widely known and observed in the community could Hume's argument begin to take effect against the pseudo-scientists, protecting us from their false and irresponsible testimony.

Let me therefore put forward what I shall call Hume's real definition of a miracle as that which his argument always does recommend that we dismiss: something that contradicts our most well-confirmed beliefs. ${ }^{12}$

Now let us take, for instance, the Biblical miracle of the raising of Lazarus. According to Hume, every dead person who never comes to life again is evidence against this miracle having really occurred, so the probability that it did not occur is running at billions to one. How sure are we that the Biblical authors were telling the truth (or the whole truth) about this situation? Hume concludes, with characteristic irony:

...upon the whole we may conclude, that the Christian religion not only was at first attended with miracles, but even at this day cannot be believed by any reasonable person without one. Mere reason is insufficient to convince us of its veracity. And whoever is moved by Faith to assent to it, is conscious of a continued miracle in his own person, which subverts all the principles of his understanding, and gives him a determination to believe what is most contrary to custom and experience. ${ }^{13}$

This all sounds very fine, a victory for naturalistic philosophy over bad arguments thrown up by the societal forces of superstition and bigotry. Yet is it? Peirce sums up his objection to Hume by saying that he "has completely mistaken the nature of the true logic of abduction. ${ }^{14}$ I will outline this objection, and then argue that it is relevant today, insofar as much contemporary naturalist philosophical methodology is deeply influenced by Hume. 


\section{Peirce and the Logic of 19th Century German "Higher Criticism"}

Peirce calls Hume's approach to miracles the "method of balancing likelihoods". He claims that it is useful in certain tightly circumscribed situations, such as when one is playing dice and trying to guess how likely it is that a certain number or set of numbers will be thrown. Thus, if I have three dice, and I want to know how likely it is that I will get a seven by throwing them, I count all the possible three-dice results that sum to seven, then work out how many possible results there are overall. Then I divide the first number by the second. However, when we are dealing with human testimony, Peirce writes, the method of balancing likelihoods can only have a pernicious effect, and he demonstrates this naturalistically by producing an interesting example of Hume's method at work in a situation where it so happens that the method's efficacy can be independently tested.

Hume claims that when dealing with testimony regarding baffling events, we should balance the likelihood of the event occurring against the likelihood that the witness is not telling the truth. A branch of nineteenth century learning devoted itself to this activity - the so-called "higher criticism" of the (mainly) German classical philologists. These scholars considered ancient texts, in which many strange events are reported, and made judgements about which of the events really happened. An empirical test for the method of balancing likelihoods arose fortuitously in the latter half of the nineteenth century, for archaeology made great advances, and many of the new archaeological discoveries bore directly on the philologists' conclusions.

Peirce is scathing about the results of this unprecedented test:

German "higher criticism" of history in general and above all of ancient history, although it has of late withdrawn from many of its most extravagant positions, is still marked by a strong disposition to discredit all the testimony which alone can give us any information about that history, in favour of what the modern German conceives to be likely. Thus, we were told that if there ever were any kings in Rome, all that has come down about them is mythical; that there never was any such poet as Homer, far less any such city as Troy, or any such state of Greek society as is described in the Iliad and Odyssey; that only a minority of the dialogues of Plato are genuine; that the writings attributed to Aristotle were gradually composed in the Peripatetic school; that Manetho's account of Egyptian history is ridiculous, etc., etc. But during our day, a great deal of excavation and of highly scientific archaeological work has been done; and none has ever been done without restoring the credit of the ancient writings. One of the most recent examples of how these German critics have infected the world with their bad judgement is to be found in a work only a few years old by the most scientific living archaeologist, I mean Mr, Flinders Petrie's History of Egypt. In this work he treats the first three of Manetho's Egyptian dynasties as altogether mythical, notwithstanding the uniform confirmation of Manetho's testimony. A few years later, it [was] Mr. 
Petrie himself who discovered monuments of Menes himself, Manetho's first king. 15

Given that the results of this "higher criticism" were so very wrong, Peirce writes that there are two possible explanations of this. The first is that the German philologists are unscientific charlatans. The second is that they are faithfully following a bad logical method. He inclines to the second explanation.

What was so wrong with their method? Peirce writes that there are many reasons why the method of balancing likelihoods is inappropriate to human testimony. First, this method requires us to sum the likelihoods of various testimonies in favour of a miraculous event occurring, for these testimonies will count as the "experiments" in Hume's terminology which require to be balanced for and against the hypothesis in question. For this to work, the probabilities of the individual testimonies would have to be independent of each other.

This is the case where we are dealing with dice throws, where (notoriously), just because the number six has been thrown three times in succession, it is no less likely to turn up again directly. Yet ancient testimonies do not have this character. Many ancient authors heard their stories from each other, or jointly from some earlier source, now lost.

Secondly, the fact that the testimony was provided has to be independent of the probability of what was related, if we are to judge it according to the probabilities we normally assign to human testimony. Again, this is not the case with miracle reports. Peirce writes:

The method of balancing likelihoods not only supposes that the testimonies are independent but also that each of them is independent of the antecedent probability of the story...But how very remote from the real state of things it is to suppose that the narration of an ancient event is independent of the likelihood of the story told! Roughly speaking, it may be said that all detached stories of Greece and Rome, were told chiefly because the writer had something marvellous to recount... ${ }^{16}$

Given that the improbability of the events recounted in ancient testimonies is contributing to the likelihood of those testimonies being related, it is wrong to treat the testimonies as a tapestry of events of the kind we ourselves inhabit: that is, a world where we observe very few improbable events, and a great many boringly probable events, and therefore where any person's testimony that their life has been studded by a series of marvels is grounds for suspicion. Rather, the boringly probable events which occurred in ancient times have been lost to history, leaving a Reader's Digest of marvels. The German philologists, however, judged ancient writers as if they were contemporaries of their acquaintance who just said too many improbable things to be believed. 
Thirdly (and most importantly), probability proper, according to Peirce, is a statistical notion, which only makes sense against a clearly defined reference class ${ }^{17}$. Thus, if a scientist attributes to me a $50 \%$ chance of dying before the age of seventy, in the background of that claim is a claim that half of all white people will die before the age of seventy, or that half of all philosophers...or some other class that includes me. For this claim to be useful to me, the reference class needs to be defined so as to include as many of the salient features of my situation as possible. ${ }^{18}$ Yet with respect to evaluating the probability of the truth of any miraculous testimony, what are the salient features? What is the reference class?

So, for instance, I might tell the truth $99 \%$ of the time, and a friend of mine might know this, but how does it help my friend to decide what I will do when someone has a gun pointed at my head asking for the whereabouts of my sister? Or (more relevantly) when I want to impress people with tales of amazing miracles? Peirce concludes that where situations are drenched with salient unique features in the way that human testimonies are, any possible reference class becomes so small that principled judgements of probability give way to subjective impressions of what is "likely". And this, he argues, is the trap into which the German philologists fell. For, he claims, where as a consequence of a poor investigative method, no answers are supplied to a group of inquirers with respect to difficult questions, this naturally creates a vacuum where arbitrary notions about what they would like to be the case rush in. Thus, the most general point that Peirce wishes to make via his examination of Hume's argument against miracles is that making judgements of probability given one's background information is a dangerous method to use to eliminate hypotheses. Peirce's discussion of the higher critics may thus be seen as establishing experimentally (thus using bona fide naturalistic methodology) that our notions about what might be true or false are just too limited and fallible for us to be able to deal probabilistically with human testimony with respect to that which contradicts what we currently believe, if we wish to correctly judge the truth or falsity of such testimony.

At this point, one may wish to object: what are we to do then when confronted by the ridiculous stories of supposedly law-breaking events which compete for the attention of the credulous and (as Hume put it) prey on people's superstitions and fears? People may be observed making large amounts of money from the alleged healing properties of crystals, from strange powers attributed to dolphins, to name just a couple of examples. If we are not to use Hume's rules to guide the understanding in situations such as these, what rules are we to use?

\section{Abduction}


Peirce's response is to suggest a better method for evaluating testimony. The key here lies in Peirce's remark, cited earlier, that Hume completely misunderstands the logic of abduction. For Peirce advocates searching for the best explanation for all given facts, which includes the testimonies themselves. He writes:

Now the first rule which we should set up is that our hypothesis ought to explain all the related facts. It is not sufficient to say that testimony is not true, it is our business to explain how it came to be such as it is. ${ }^{19}$

Peirce saw abduction as the missing third term in traditional analyses of logic, which restrict themselves to deduction and induction. By including abduction Peirce quite deliberately expands the subject matter of logic to include scientific method. Abduction bears some structural similarity to what is currently termed "argument to the best explanation" 20 :

The surprising fact, $\mathrm{C}$ is observed.

However, if $\mathrm{A}$ were true, $\mathrm{C}$ would be a matter of course.

Hence there is reason to suspect that $\mathrm{A}$ is true. ${ }^{21}$

Abduction happens naturally to everyone when they meet something baffling, and its role is purely to generate hypotheses that would explain the baffling thing, if true. Testing and weighing the probability of the hypotheses generated by abduction, however, is a matter for another form of inference, namely induction.

The course which any inquiry follows according to Peirce has three broad stages. First comes a surprise of some sort, which triggers the inquiry. Imagine for instance that one's morning bus unexpectedly fails to arrive. Using abduction one generates possible explanations for the surprising phenomenon. Thus one might speculate that the day is a public holiday one did not know about. One then moves to the second stage, namely deduction, which traces out the consequences of the hypotheses provided by abduction. (For instance, one might reason, "If it is a public holiday, then this will be listed in my diary".) Finally there is induction, which searches for those consequences in some clearly defined and publically repeatable experiment. (One might take out one's diary and look at it). If all goes smoothly, and the hypothesis is confirmed, one will have a new belief to add (provisionally) to one's store.

Due to its role as a pure hypothesis-generating mechanism, abduction delivers no probability to its conclusions. At the start of Peirce's career he believed that abductions delivered some (very weak) degree of probability to their hypothetical conclusions. However he soon realised that although an abduction may be said to confer a degree of plausibility on its conclusion, the conferring of (numeric) probability is entirely the role of inductive inference, and induction and abduction are entirely distinct inference forms with distinct virtues ${ }^{22}$ Abduction is, however, the 
most productive of the three inference forms in the sense that it is the only inference form which introduces new ideas into our thinking. Induction only tests a suggestion already made. Deduction merely teases out the necessary consequences of what we already suppose. Yet without new hypotheses science would grind to a rapid halt.

How may this model of inquiry be applied to baffling human testimony? Interestingly, according to Peirce the best explanation may be different from the account given by either a simple acceptance of the testimony, or a simple rejection of it. Let us imagine a modern-day miracle story. Imagine that John remarks that his father was clinically dead for two hours, but was then raised from that state by judicious use of a crystal. What is one to do with this story? Hume would say that, as millions of people have died and never been raised, there is much more chance that John is speaking falsely than that what he is saying is true. Thus, one should disbelieve him and think no more about the matter.

Now, how does Peirce advocate that we distinguish between hard-to-explain (but true) facts and illusory phenomena or fictitious miracles? First of all, where one is dealing with a phenomenon that is directly perceived (that is, with the "testimony" of one's senses) one must check one's perceptual conditions, for often a simple alternative explanation for the appearance of the phenomenon can be had there. (The famous underwater "bent" stick is a case in point here). Secondly, one must see if one can repeat the phenomenon publically, for if anything is to be inferred from the phenomenon inductively in the long run, it will need to be publically accessible, according to Peirce's notion of induction. Suspicion will be thrown on the testimony of others to the degree that the phenomena testified to are not susceptible to public repetition. If miraculous testimony stands up to these two tests, it is time to consider possible explanations which "save" the phenomenon, though this might happen in any number of ways.

Applying Peirce's method to John's miraculous testimony, two hypotheses naturally suggest themselves:

i) The crystal alluded to by John has previously unknown physical powers. What consequences can one deduce from this hypothesis? If the hypothesis is true it appears, at least prima facie, that the crystal should be able to raise other dead people, and that the crystal will have some sort of unique structure which allows it to perform a feat not performed by other physical objects which come in contact with dead people, such as shrouds and coffins. These consequences can be tested (and once this is done they will most probably undermine the probability of the hypothesis).

ii) John is not telling the truth. What consequences follow from this second hypothesis? Possibly John will have lied in such a way in the past. Possibly he will have something to gain financially from the deception. John's father, if interrogated, 
may admit that in fact he was never dead, and there may be no death certificate. All of these consequences can be tested if we want to get to the bottom of this modern-day Lazarus story.

iii) However, other hypotheses are quite possible! Here is a third: John's father, who shares his son's interest in New Age phenomena, possesses a natural and previously undiscovered talent for self-hypnosis. Pursuing this hypothesis could turn up some very interesting facts. It could also turn out to be entirely false ${ }^{23}$. Nevertheless, the possibility of hypotheses such as this (and many more) should be acknowledged.

Of course it would be tedious to set ourselves to testing every miraculous testimony we came across. We would be spending most of our lives investigating purported Elvis sightings and chasing UFOs around lowly populated areas. In most cases we set such stories aside, but the important point is that we do so not because we have performed a Humean quantitative comparison of how probable it is that our interlocutor is speaking falsely and how probable it is that, say, crystals could raise people from the dead. What we have done is sketch a rough outline of a better explanation for the testimony than that the miracle described actually happened. (With respect to unscrupulous New Age testimony, this better explanation often involves financial incentive.) However, this better explanation is still only a hypothesis, which may be overturned later in the light of further evidence.

Though Hume and Peirce's methods will most probably deliver the same result with respect to the modern-day Lazarus story, they part ways in other circumstances. I related earlier the story of the Indian prince, who refused to accept the testimony of his European visitors regarding ice, and moreover went on to reject other things the travellers had told him. Hume claimed that the prince reasoned "justly", for it was much more likely that that foreigners were lying than that water would do such an unconscionable thing. But did he?

Our prince did not have much of a scientific mind, as there was plenty of scope for hypothesis-testing here. Again, two hypotheses seem natural:

i) The story about ice was true. What consequences could the prince have deduced from this hypothesis? From the limited description of the case, it seems that he could have reasoned that the Himalayas are also cold, and so he could have spoken to someone who had been there, to see if they described the same phenomenon. He could have searched through Indian folk-tales for tales of cold lands. Either test would most probably have confirmed the hypothesis.

ii) The story was false. Possible consequences here include that if one took the travellers aside and questioned them about minor details of the story, such as the temperature at which water did this strange thing, they would disagree, or that they were generally deceptive people who lied to each other. They might be making their 
way around SouthEast Asia dining out on stories of the amazing miracles that occur in Europe. This could most probably be checked.

If the prince had proceeded this way, he would have eventually found out the truth about ice. As it was he completely missed out on the opportunity to learn something. The important difference between Hume and Peirce's methods, then, is in their attitude to the baffling, that which contradicts our most well-confirmed beliefs about the world. For Hume, the possibility of such a phenomenon is to be cast aside on principle. For all our evidence for the laws of nature is evidence against the phenomenon. For Peirce such a phenomenon is potentially valuable as it presents an opportunity for inquiry, a chance to find out something new.

\section{4.. Contemporary Naturalism}

In this section of the paper I shall suggest that the considerations Peirce raises against Hume are not of purely historical interest. Much work in contemporary "naturalist" philosophy is, I believe, Humean rather than Peircean in its attitude to that which apparently contradicts our most well-confirmed beliefs. For the purposes of this paper I will concentrate on a single naturalist whom I shall take as a case study, and that is Frank Jackson, whose naturalism (which he calls "physicalism" ${ }^{24}$ ) is particularly clear and carefully developed.

Jackson's 1994 paper "Armchair Metaphysics"25 addresses itself to the question of what the consequences are for metaphysics, which was once the very trunk of the tree of knowledge in Descartes' vivid metaphor, of the rapid and almost overwhelming growth of the tree's branches (the physical sciences) since the seventeenth century. $\mathrm{He}$ addresses himself to the question of how one ought to do metaphysics now, in the light of these developments.

It might seem as if philosophy should "move over", leave claims about the fundamental character of the Universe to the physical scientists, and content itself purely with some form of conceptual analysis. However Jackson claims that metaphysics, though it should see conceptual analysis as one of its major tools, should retain its role as "speculative cosmology":

Metaphysics...is about what there is and what it is like. But of course it is not concerned with any old shopping list of what there is and what it is like. Metaphysicians seek a comprehensive account of some subject matter - the mind, the semantic, or, most ambitiously, everything - in terms of a limited number of more or less basic notions. In doing this they are following the good example of physicists. ${ }^{26}$ 
As well as a unified explanation for everything, Jackson claims that physicalism provides a complete explanation for everything. Once the physicalist world-story has been told, there is nothing further to say about the universe. ${ }^{27}$

This idea of a complete world-story told in terms of just a few physical properties and relations leads to what Jackson calls the location problem. If one imagines that the world is an enormous spatiotemporal container, and that each piece of the total world story "fills in" some of the container by referring to the events/entities/properties/relations that exist there, Jackson's claim is that the total physicalist world story fills in the whole of the container. How then is there room for statements involving non-basic notions to be true? An example Jackson uses to illustrate the location problem is "the semantic" (truth and meaning, considered as properties of sentences). He writes:

Some physical structures are true. For example, if I were to utter a token of the type 'Grass is green', the structure I would thereby bring into existence would be true...The object I would thereby bring into existence would also have a certain mass and length (or duration), a certain causal and evolutionary history, be of a type the other tokens of which have characteristic causes in my mouth and from my pen...have a certain structure the parts of which have typical causes and effects, and so on and so forth. How are the semantic properties of the sentence related to the non-semantic properties of the sentence? Where, if anywhere, are the semantic properties of truth, content, and reference to be found in the non-semantic, physical or naturalistic account of the sentence? ${ }^{28}$

One might ask, why should it be the semantic which requires "location" amongst the physical, and not vice versa? Implicit in the way this problem is set up seems to be the argument that this is because of the extremely well-confirmed nature of our beliefs about physical properties. Somehow the success of the physical sciences at providing explanations is being invoked. Jackson claims to be committed to the physicalist's "favoured terms" being, "broadly of a kind with those that appear in current physical science" ${ }^{, 29}$. He assumes that whatever the favoured list of terms turns out to be, properties such as "the semantic" will not be on that list. ${ }^{30}$

But why does the existence of the semantic alongside the physical trigger the location problem rather than, say, merely providing extra properties to add to our physicalist description of sentences? This crucial step in Jackson's argument is provided by physicalism's claim to completeness, mentioned earlier. Physicalism's claim is not just that a particular set of favoured terms accurately describes the Universe, but that it describes all of the Universe. It is this crucial component of physicalism which drives mere descriptive dissonance between the semantic and the physical into contradiction: 
Physicalism is not simply the doctrine that the world has lots of physical nature. That is not controversial: nearly everyone agrees, for instance, that objects have mass, charge and density, and that there are gravitational and electrical force fields. The physicalist's distinctive doctrine is...that the world is entirely physical in nature....and that a full inventory of the instantiated physical properties and relations would be a full inventory simpliciter. ${ }^{31}$

Jackson claims to have an answer to the location problem which lets us locate "the semantic". The answer is entry by entailment. According to Jackson's account of supervenience, any world that contains the physical properties that make up the sentence "Grass is green" must contain its semantic properties also. It is not possible for those particular physical properties to occur without those semantic properties also occurring, and in this way the existence of lower level physical properties can be said to entail the existence of higher-level properties such as semantic properties, which is the only way they can be given "ontological respectability".

I argued that Hume's real definition of a miracle was something that contradicts our most regularly confirmed beliefs. He argues that when confronted with something of this nature, we should consider all our evidence for those regularly confirmed beliefs as evidence against the miracle, and reject it accordingly. Yet Jackson's problem with the semantic is precisely of this nature. "The world's physical nature" ${ }^{32}$ in Jackson's argument is given the privileged place which in Hume's argument is accorded to "laws of nature". "The semantic", on the other hand is given the status of a phenomenon merely testified to. It is testified to in non-scientific contexts when people ${ }^{33}$ describe sentences as true or false, and as meaning certain things.

Of course Hume's miracles and Jackson's "semantic" differ in that miracles arouse wonder, yet what could be more ordinary than a sentence being true or false? However, the issue this paper is concerned with is our treatment of what apparently contradicts our most favoured beliefs, and the two cases share this feature. Indeed, Jackson seems to manage to work himself into a state of genuine bafflement when he asks how the semantic could so much as find a place in his entirely physical Universe:

We might respond with a sceptical or eliminativist position on truth, meaning and reference...if the complete account does not contain truth, reference and meaning, then so much the worse for truth, reference and meaning, runs the sceptical response. ${ }^{34}$

Jackson considers only two alternative solutions to his location problem. The first is "elimination", which corresponds to Hume's rejection of miraculous testimony. The second is "location", through "entry by entailment", by which he means some form of demonstration that the anomalous semantic testimony is nothing but a necessary consequence of the fundamental laws of nature, which remain fundamental after the anomaly has been "located" amongst them. 
I would like to suggest a better approach to this situation, which is analogous to the better approach to Humean miracles already outlined. That is, to at least put on the table the possibility that some abduction, or series of abductions, can be generated that will explain both Jackson's (physical) laws of nature and the rogue (semantic) testimony he seeks to "locate". We have seen that Peirce advocates a three-stage approach to testimony which contradicts our most well-confirmed beliefs, involving first checking perceptual conditions, then attempting to repeat the experience publically, and finally searching for hypotheses which would explain the phenomenon testified to. Testimony about the truth and meaning of sentences easily passes the first two stages, for it is widely agreed to, teachable, and the phenomena in question are in fact in some sense essentially public (as the later Wittgenstein and others have noted).

If it appears that the physical and the semantic do not mesh explanatorily despite in some sense describing the same things (that is, sentences), then maybe this is an opportunity to improve our knowledge of the semantic and the physical. Why should Jackson assume that if we cannot have "location" of the semantic, we must have "elimination"? A third possibility is unification, whereby two explanatory schemes fuse in a new explanatory scheme that draws from both of them, but also (via abduction) adds ideas that are new.

It is somewhat ironic the way in which Hume and Jackson in their arguments against their respective "miracles", make liberal use of our desire to avoid contradiction. Hume argues that to accept testimony that a miracle had occurred would contradict the laws of nature. Jackson argues that taking talk of the semantic at face value would contradict physicalism. Both these arguments slide from the new and different to the contradictory in a manner which is odd given the other commitments of these philosophers. Hume assumes that where the relation, "if A then $B "$, is established as a law of nature, if A is followed by $\mathrm{C}$, we have a violation of, "if A then B", a putative miracle and something to be dismissed. In order to get that result he must be assuming not only that our "uniform experience" delivers us knowledge of laws of nature, but that it delivers us the modal knowledge that these regularities cannot be interrupted.

But this is not very "Humean"! It was Hume himself who argued, in his famous discussion of induction, that just because $\mathrm{A}$ has been followed by B indefinitely many times, there is no contradiction in supposing that A may one day suddenly be followed by C. Some of Hume's contemporaries took great delight in pointing this out to him. ${ }^{35}$ I would urge a similar point with respect to Jackson who assumes, in his claim of "completeness", that it is part of physicalism that properties and relations "broadly of a kind with those that appear in current physical science", provide a total 
explanation of the Universe. For a position supposedly inspired by the success of the natural sciences, how might it be empirically established?

This paper has concerned itself with what to do when faced with the baffling, that which apparently contradicts our most well-confirmed beliefs. Peirce goes so far as to suggest that it is their attitude to the apparently contradictory, investigating it when it arises and even (perversely) seeking it out, which distinguishes true scientists from other types of person. ${ }^{36}$ Peirce claims that, based on the behaviour he has witnessed, it is as if science and philosophy have had their etymologies interchanged. For "science" comes from a word meaning "knowing" and "philosophy" from "love of wisdom". He writes:

The derivations of words would better fit the facts if science and philosophy were to swap names. For it is the philosophers who burn to teach the world their absolute systems of doctrine, while the scientific men are incessantly engaged in struggles to learn the truth - struggles which imply their dissatisfaction with the existing state of their knowledge and consequently with any rounded systematisation of it. ${ }^{37}$

Insofar as Hume and latter-day Humeans such as Jackson rely on a methodology of inquiry which omits abduction, they omit the generation of original ideas in hypothetical form to explain phenomena which contradict current beliefs. They thus commit to an essentially conservative, quietist approach to inquiry, where a set of beliefs is held sacred and anomalies (if "unlocatable") are rejected, leaving the set of beliefs intact. By taking abduction seriously, then, as part of the scientific method, and indeed of logic, one may develop a method for examining baffling phenomena that will be as effective as Hume's method in banishing "arrogant bigotry and superstition", yet not fall into the mistakes of the German philologists and the Indian prince in dismissing phenomena that contradict our current well-confirmed beliefs on those grounds alone. Perhaps even more importantly, such a method restores to human naturalistic inquiry the fundamental role played in it by amazement. ${ }^{38}$

\section{RESEARCH SCHOOL OF SOCIAL SCIENCES AUSTRALIAN NATIONAL UNIVERSITY, ACT, 0200 \\ AUSTRALIA}

\section{REFERENCES}

C.A.J. Coady, Testimony: A Philosophical Study, Oxford: Oxford University Press, 1992.

J. Earman, Bayes or Bust, Massachusetts: MIT Press, 1992. 
Carolyn Eisele, ed., Historical Perspectives on Peirce's Logic of Science: A History of Science, Vol. Two, Berlin/New York/Amsterdam: Mouton, 1985.

Ian Hacking, The Taming of Chance, Cambridge: Cambridge University Press, 1975.

David Hume, A Treatise of Human Nature, ed. L.A. Selby-Bigge, Oxford: Oxford University Press, 1978.

David Hume, "Of Miracles", section X, Enquiry Concerning Human Understanding, Oxford: Oxford University Press, 1975.

Frank Jackson, "Armchair Metaphysics", The Place of Philosophy in the Study of the Mind, ed. M. Michael and J. O'Leary-Hawthorne, Dordrecht: Kluwer, 1994, pp. 23-42.

Frank Jackson, From Metaphysics to Ethics: A Defence of Conceptual Analysis, Oxford: Oxford University Press, 1997.

Jon and Susan Josephson, Abductive Inference, Cambridge: Cambridge University Press, 1994.

Michael P. Levine, Entry on "Miracles", Stanford Encyclopedia of Philosophy. http://plato.stanford.edu/entries/miracles/miracles.html, downloaded 8th November 1996.

John Locke, An Essay Concerning Human Understanding, abridged and ed. by A.D. Woozley, London: Fontana, 1960.

Kenneth R. Merrill, “Hume's 'of Miracles', Peirce, and the Balancing of Likelihoods", Journal of the History of Philosophy 29(1), 1991, pp. 85-113.

C.F.D. Moule, ed., Miracles, London: Mowbray \& Co., 1965.

David Owen, "Hume versus Price on Miracles and Prior Probabilities: Testimony and the Bayesian Calculation", Philosophical Quarterly 37, 1987, pp. 187-202.

Charles S. Peirce, Philosophical Writings of Peirce, ed. J. Buchler, New York: Dover Publications, 1955.

Charles S. Peirce, Collected Papers, Massachusetts: Harvard University Press, 1933 \& 1935, Vol.s 1, 2, 5, 6 .

Charles S. Peirce, "The Logic of Drawing History from Ancient Documents", in Eisele, C., ed., Historical Perspectives on Peirce's Logic of Science: A History of Science, Volume Two, Berlin/New York/Amsterdam: Mouton, 1985.

Charles S. Peirce, Reasoning and the Logic of Things: Cambridge Conferences Lectures, 1898, ed. K. Ketner, Massachusetts, Harvard University Press, 1992. 


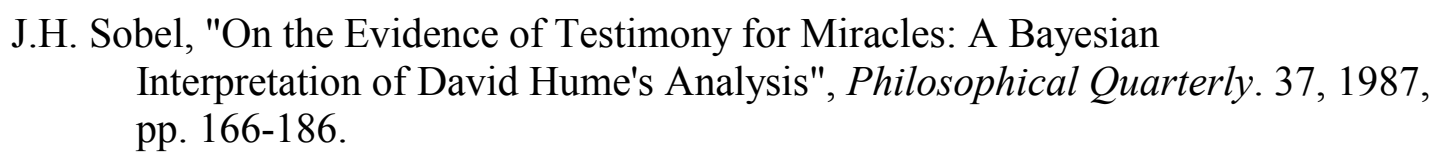

Stanley Tweyman, ed., Hume on Miracles., Bristol: Thoemmes Press, 1996.

\section{NOTES}

1 Although this leaves aside the vexed question of whether if miracles were to take place, in what sense this would demonstrate, prove or suggest that the Christian (or any other variety of) God existed. This issue is sensitively explored in Moule, C.F.D., ed.. Miracles. (London: Mowbray \& Co., 1965), which is a collection of essays presented to the Cambridge University New Testament Seminar.

2 Other definitions of naturalism exist which make not methodological but substantive ontological claims about the Universe's most basic ingredients. But such naturalisms are hostage to scientific fortune in a way that methodological naturalism is not. Moreover, it is arguable that it was the development of the experimental method rather than any particular ontological claims made by 17 th century natural scientists which enabled the large leap forward which the natural sciences took at that time, and which the "naturalistic" philosopher should therefore seek to emulate.

3 This phrase from the pragmatist philosophical tradition has been chosen deliberately instead of the less specific, and less obviously connected to logic, "epistemology".

4 David Hume, "Of Miracles". Section X, Enquiry Concerning Human Understanding. (Oxford: Oxford University Press, 1975), p. 114.

Ibid, p. $115 \mathrm{n}$.

Ibid, p. $110-1$.

This story is also related by John Locke An Essay Concerning Human Understanding (London: Fontana/Collins, 1976, IV, xv, 5), though here it takes the form of the King of Siam and a Dutch ambassador. As such it bears telling signs of being an Early Modern epistemologist's folk tale (which does not of course diminish its usefulness in illustrating Hume's adherence to the principle which the tale is meant to embody).

8 Hume, "Of Miracles", p. 111.

9 "In all cases, we must balance the opposite experiments where they are opposite, and deduct the smaller from the greater, in order to know the exact force of the superior evidence." Ibid, p. 111.

10 Ibid, p. 110.

11 This is also remarked on by Peirce, Collected Papers (Massachusetts: Harvard University Press, 1935, 6.537). Michael Levine, whose claim to speak authoritatively on this subject seems established by his having written a PhD thesis and a book solely on Hume's discussion of miracles: Hume and The Problem of Miracles: A Solution, (Dordrecht: Kluwer, 1989). In his entry, "Miracles" in the Stanford Encyclopedia of Philosophy, Levine writes that "...the premise that 'a miracle is a violation of a law of nature' plays no significant role in his argument." (http://plato.stanford.edu/entries/miracles/miracles.html, p. 2)

12 One might argue that once one factors in Hume's "anti-metaphysical" account of causation, the distinction I am drawing between so-called metaphysical and epistemic miracle definitions cannot be sustained within Hume's system. Maybe so, but in the article "on Miracles" Hume seems to actively vacillate between these two interpretations, which can certainly be separated in principle. Hume, "Of Miracles", p. 131.

Charles Peirce, ibid, 6.537.

15 Charles Peirce, "The Logic of Drawing History from Ancient Documents", in Eisele, Carolyn, ed. Historical Perspectives on Peirce's Logic of Science: A History of Science, Volume Two (Berlin/New York/Amsterdam: Mouton, 1985), p. 910.

16 Ibid, p.911.

17 Thanks to Tom Anderson for helpful discussions on this point.

18 Compare, "Half of all the Universe's sentient life-forms will die before the age of 3000", which may well be true, but is not at all useful to me.

19 Charles Peirce, Collected Papers, 7.225. 
20 This term was coined by Gilbert Harman and introduced into Anglo-American philosophy in the 1970s. However, we will see that the two are different in that abduction is not a provider of explanations but a provider of hypotheses, which may or may not ultimately be accepted as explanations, based on the application of further forms of inference.

21 Peirce produced many different formulations of the abductive argument over his long and inventive logical career. This is a classic later formulation, dating from 1901, and taken from Philosophical Writings of Peirce, ed. Justus Buchler, (New York: Dover Publications, 1955), p. 151.

22 So although the number of plausible hypotheses which might be generated to explain a particular phenomenon might be large, the criteria by which scientists select the very few hypotheses that they will actually test are not probabilistic but "economic". Unfortunately space does not permit me to discuss this interesting issue any further here.

23 Which is not to say that pursuing it would necessarily therefore have been fruitless, for investigating false hypotheses can be of great use in narrowing the field of possible true hypotheses. See, for example, Peirce's discussion of the decoding of cunieform script in Collected Papers, 7.220 .

24 Various distinctions may be drawn between the terms "naturalism' and "physicalism", but I have assumed that they are not relevant for the purposes of this paper. It will be obvious I hope that by "physicalism" Jackson means at least a privileging of the methods of science with respect to discovering the way the world is, which is how I have defined naturalism.

25 Frank Jackson, "Armchair Metaphysics", The Place of Philosophy in the Study of the Mind, ed. M. Michael and J. O'Leary-Hawthorne (Dordrecht: Kluwer, 1994), pp. 23-42.

26 Ibid, p. 25.

27 "...when you have said all there is to say about physical properties and relations you have said all there is to say about everything." Ibid, p. 27.

28 Frank Jackson, From Metaphysics to Ethics: A Defence of Conceptual Analysis (Oxford: Oxford University Press, 1997), p. 2.

29 Ibid, p. 7.

30 With respect to the topic of this paper, it is interesting to note that Jackson also claims that, "...the necessary being that some theists believe in has properties that have no place in physical science." Ibid, p. 22.

Ibid, p. 9.

Ibid, p. 9.

(colloquially known in Australian philosophy as "the folk")

Ibid, p. 2.

35 So, for instance, Anthony Ellys wrote in 1753, "...if the Laws of Nature were unalterably fixed, the Consequence is plain, that every Miracle, which imples at least a temporary Suspension of those Laws, or an Effect contrary to them, would be impossible. But I think this can hardly be our Author's Meaning; because a Person of his Capacity must have seen that our Experience cannot be a sufficient proof that the Laws of Nature are unalterably fixed."

An anonymous author wrote in the Monthly Review, February 1767, "A miracle is more properly an event different from experience than contrary to it... what information would experience give? - It would only tell me what happened on other occasions, and in other instances...for it can be no part of any one's experience, that the course of nature will continue always the same." These contemporary responses to Hume on miracles, and others, have been collected by Stanley Tweyman into a useful book, Hume on Miracles (Bristol: Thoemmes Press, 1996).

36 This is a point worth making against those who regard science with fear and loathing as an attempted hegemonic world-view, a modernist meta-narrative or "theory of everything". Peirce, "The Logic of Drawing History from Ancient Documents", p. 1122.

38 In writing this paper I have benefitted greatly from discussions on the email list "Peirce-L" (peirce-1@ttacs6.ttu.edu), particularly with Tom Gollier and (the late and sadly missed) Tom Anderson. Thanks are also due to Huw Price, Stephen Buckle, Neil McKinnon, Jim Franklin, Andrew Gleeson, Steve Clarke and Peter Alfeld for help and advice, and an anonymous reviewer for some useful comments. 